\title{
Development and Test of World's First Industrial High-Temperature Superconducting (HTS) Power Cable
}

\author{
U. K. Sinha \\ D. T. Lindsay \\ R. L. Hughey Jr. \\ Southwire Company \\ Carrollton, GA 30019 USA
}

\author{
J. P. Stovall \\ M. J. Gouge \\ J. W. Lue \\ Oak Ridge National Laboratory \\ Oak Ridge, TN 37831 USA
}

\author{
P. Haldar \\ V. Selvamanickam \\ N. Vo \\ Intermagnetics General Corp. \\ Schenectady, NY 12100 USA
}

\begin{abstract}
Southwire Company has installed the world's first industrial high-temperature superconducting cable system to power three of its main manufacturing plants. The cable consists of three single-phase, $30-\mathrm{m}$ long cables designed to carry $1250 \mathrm{~A}$ at $12.4 \mathrm{kV}$. The cable is cooled by a liquid nitrogen (LN) system that can supply LN at sub-cooled temperatures down to $72 \mathrm{~K}$ and at pressures up to 15 atmospheres. The design of the $30-\mathrm{m}$ cables is based upon two 5-m cable prototypes, which were tested at a specially developed facility at ORNL. In addition to critical current and ac loss measurements, simulated fault-current tests were performed at ORNL on the 5-m cables. Cable terminations were designed to allow smooth transition from the cryogenic temperature and pressure environment of the HTS cable to ambient temperature and pressure for copper cables. A dielectric tape material, Cryoflex ${ }^{\mathrm{TM}}$, was also developed for use at cryogenic temperatures.
\end{abstract}

Keywords: Power cable, superconducting cables, hightemperature superconductors, superconducting transmission lines, superconducting filaments and wires, power transmission lines, cryogenics.

\section{INTRODUCTION}

$\mathrm{S}$ outhwire Company is demonstrating the world's first industrial application of high-temperature superconducting (HTS) power cables with a 30-m, three-phase cable system at its Carrollton, Georgia plant as shown in Fig. 1. The three 30-m cables are shown in the center. To the left and right of the cable is the switchyard used to energize the cable. Behind the cables are the LN storage tank and the cryogenic system. The cable carries $1250 \mathrm{~A}(\mathrm{rms})$ at $12.4 \mathrm{kV}$ and powers two of its main manufacturing plants and the Southwire Machinery Division.

The cable was developed in close collaboration with Oak Ridge National laboratory (ORNL) under a DOE sponsored Superconductivity Partnership Initiative (SPI). Other SPI partners on this project were Argonne National Laboratory (ANL), Intermagnetics General Corporation (IGC), EURUS Technologies, Southern California Edison, Southern Company, and Georgia Transmission Corporation.

The first industrial demonstration of a three-phase, HTS power transmission cable at the Southwire manufacturing complex is in progress. This paper describes some of the development work with 5-m cables, field testing, and operation of the 30-m HTS cable system.

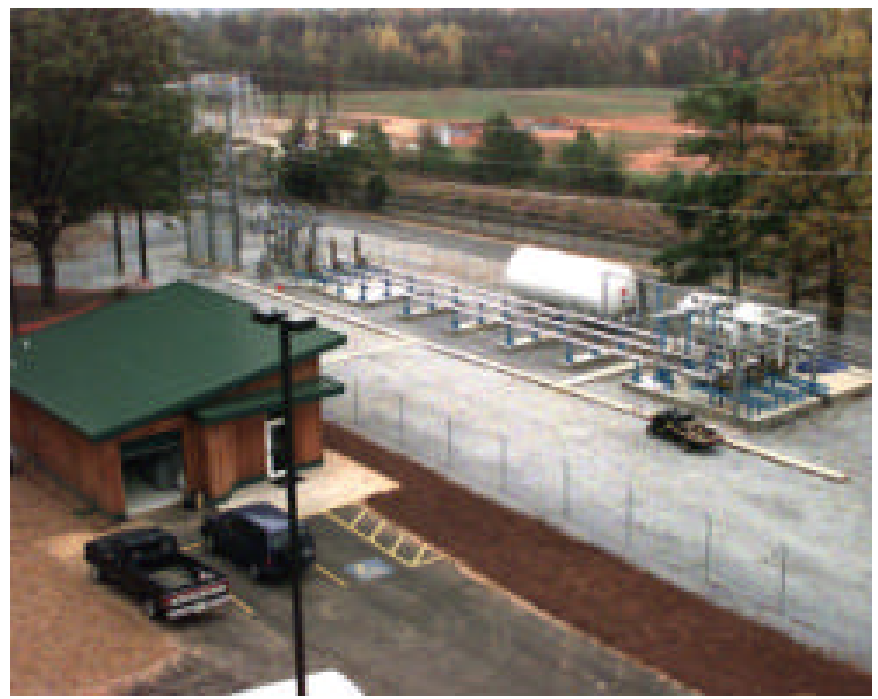

Fig. 1. The high-temperature superconducting cable installation at Southwire Company, Carrollton, Georgia.

\section{HTS TAPE}

Superconducting cable performance greatly depends upon the quality of the HTS tapes - their physical and mechanical properties. IGC- Superpower, a wholly owned subsidiary of IGC, supplied $1^{\text {st }}$ generation of HTS tapes required for the construction of 1-m, 5-m, and 30-m cables.

\section{A. First Generation Tapes}

The $1^{\text {st }}$ generation HTS material refers to compositions of bismuth, strontium, calcium, and copper oxide (Bi-2223) and is usually referred to as BSCCO. The most common fabrication process uses a powder-in-tube (PIT) method, where ceramic materials are packed in silver or silver-alloy tubes that then undergo a series of thermo-mechanical steps resulting in a superconducting tape. The tapes used in this project are 3.5 $\mathrm{mm}$ (137 mils) wide and a $0.2 \mathrm{~mm}$ (8 mils) thick. The PIT BSCCO is a relatively mature technology and several other companies besides IGC produce tapes in long lengths. The PIT BSCCO tapes have been used to demonstrate the performance benefits of a variety of HTS power devices including transmission cable, transformers, fault current controllers, motors, and generators.

During the Southwire HTS cable program, the performance improvement of the superconducting tape is shown in Fig. 2. The measured critical current, $\mathrm{I}_{\mathrm{C}}$, for the phase 2 main conductor of the 30-m HTS cable was 2980 A and an $n$-value of 9 
was observed. The critical current is the current that produces a voltage drop of $1 \mu \mathrm{V} / \mathrm{cm}$, below which the conductor is defined to be superconducting. The $n$ value from the V-I curve is defined by the power law: $\rho=k \cdot J^{n}$, where $\rho$ is cable resistivity (proportional to voltage drop), and $J$ is the current density. The critical current of the phase 1 main conductor was more than $3000 \mathrm{~A}$ (the limit of the power supply). The critical current of one of the 5-m cables is also shown in Fig. 2 and is $1090 \mathrm{~A}$ with an $n$-value of 3 .

The design current of the 5-m and 30-m cables was 1250 $A$ and the same number of layers and superconducting tapes were used in both the 5-m and 30-m cables. However, in the 15 months that elapsed between procurement of the superconducting tapes for the 5-m and the 30-m cables, the tape performance improved dramatically. As a result, the 30-m cables while designed for a 1250 A rating, are actually 3000 A conductors. With this extra margin, the superconductors contribute no resistance when operating at currents below about 1500 A, as shown in Fig. 2.

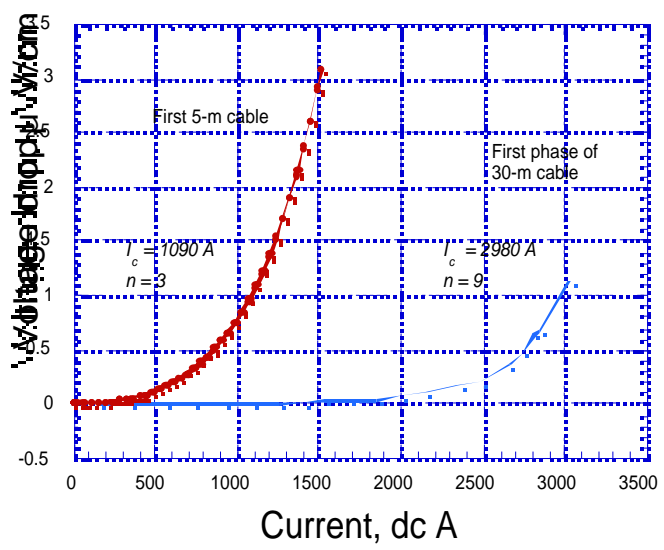

Fig. 2. Relative performance improvement of the BSCCO tapes between the 5-m and 30-m cables as measured by the critical current.

The tape performance improvements were achieved by PIT process improvements and a change from a silver clad tape for the 5-m cables to a silver-alloy clad tape in the $30-\mathrm{m}$ cables. This later change increased the mechanical strength and bending strain of the tapes, key factors in cable manufacture. The BSCCO HTS tapes produced by the PIT process has achieved sufficient critical current making them suitable for use in power cables.

\section{B. Second Generation Tapes}

Nonetheless, work has continued with the development of a $2^{\text {nd }}$ generation conductor, a coated conductor, which offers inherent ruggedness, performance, and cost benefits using yttrium-barium-copper oxide (YBCO) as the ceramic superconducting material.
YBCO is fabricated in a variety of ways by a continuous, as opposed to the batch process as in PIT. Basically, the process entails depositing a ceramic buffer layer on a metal substrate such as stainless steel or nickel and then adding a thin coating of YBCO. Typical buffer layers are yttriastabilized zirconia (YSZ) or magnesium oxide $(\mathrm{MgO})$. This is a critical step because the grains of the buffer form a very carefully aligned template onto which the HTS is deposited. The buffer layer also serves to isolate the substrate and HTS so there are no adverse chemical reactions. YBCO is deposited on the buffer layer by pulsed laser deposition (PLD), metal organic chemical vapor deposition (MOCVD) or other mechanisms.

To date, YBCO has not been fabricated in lengths greater than 1 to 5 meters. IGC-SuperPower is in the process of developing the YBCO tapes in collaboration with Los Alamos National Laboratory and ANL using a IBAD/PLD (ion beam assisted deposition for the substrate and PLD for HTS). IGC-SuperPower intends to scale-up this process for longlength YBCO conductor manufacturing and use the coated conductor for the commercial manufacturing of HTS electric power device components and the HTS power cables.

The rolling-assisted biaxially textured substrate (RABiTS) process, winner of a $1999 \mathrm{R} \& \mathrm{D} 100$ award, is another competing process being developed to manufacture the $2^{\text {nd }}$ generation of superconductor wire. In separate efforts, ORNL is collaborating with five U.S. companies - American Superconductor, 3M Corporation, Microcoating Technologies, Oxford Superconducting Technology and EURUS Technologies - to develop various aspects of RABiTS which is the template upon which the YBCO is deposited. It is made from roll-textured and annealed metals, such as nickel or nickel alloys, and one or more ceramic buffer layers. The superconducting YBCO is deposited on this template using a variety of techniques. The highest-performing short samples of RABiTS-based superconducting wire can carry 3 million amps per square centimeter at $77 \mathrm{~K}$. One meter lengths of YBCO on RABiTS were recently demonstrated by the ORNL and 3M Corporation team. Their lengths, flexibility, comparatively low cost, and current carrying capacities make RABiTS substrates ideal for high-temperature superconducting wires. Further development of the RABiTS process could lead to many industrial or commercial applications of superconductivity where none presently exist.

\section{DESIGN OF CABLE}

Based upon cable efficiency goals, Southwire has chosen to use the cryogenic dielectric design of cable construction as shown in Fig. 3. In this coaxial conductor design, HTS tapes are wound over a hollow former to construct the inner conductor that is the phase conductor for the cable. Then, dielectric tapes are wound over the HTS phase conductor followed by an outer layer of HTS tapes. The outer HTS tapes act as a shield to prevent the magnetic fields from interacting with external conductors including adjacent phases. Eddy currents are also not developed in metallic parts of the enclosure, thus eliminating any losses due to the heating. However, the cryogenic design requires that the dielectric be cooled to the minimum operating cryogenic temperature. Southwire has developed a proprietary dielectric material, Cryoflex, which is suitable for our application and will be 
discussed later.

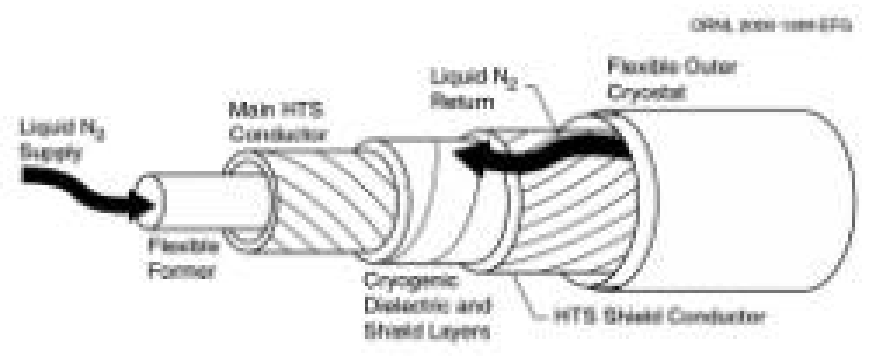

Fig. 3. Cross section for a cold (cryogenic) cable design.

\section{PROOF OF DESIGN- 5-M CABLES}

Two 5-m long cables were constructed using the same design as to be used for the 30-m cables. The 5-m cables were designed to carry $1250 \mathrm{~A}$ at $12.4 \mathrm{kV}$ similar to our final cable. A versatile cable test facility was designed and assembled at ORNL to test the prototype cable as shown in Fig. 4.

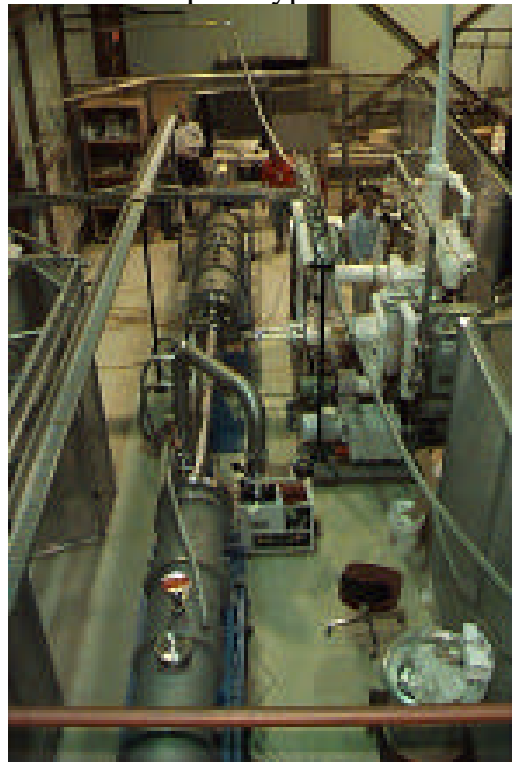

Fig. 4. The 5-m cable test facility at ORNL.

The photograph shows a 5-m cable between two terminations. A LN cooling system is shown on the right. The test facility has a $3000 \mathrm{~A}$ dc power supply for measuring the dc critical current, Ic, of the cable. A 1500 A ac power supply for measuring ac losses. A high voltage power supply is available to test the cable at a peak voltage of 2.5 times the operating voltage. An impulse power supply is also available to test the cable under impulse voltages of up to 100 $\mathrm{kV}$. The impulse generator has been recently upgraded to generate up to $200 \mathrm{kV}$. A $25 \mathrm{kA}$ pulsed power supply is also available to simulate over currents due to system faults.

The termination shown in Fig. 4 is our earlier termination that uses a high vacuum for both electrical and thermal insulation. In this termination design, two cryogenic (cold) bushings are required as feedthroughs for the phase and shield conductors. The HTS cable is separated from the termination by the cryogenic bushings for the phase and shield conductors. Inside the termination, the cold bushings are electrically connected by copper straps, which bring power from cryogenic temperature to ambient. Thermal insulation is maintained by high vacuum inside the termination. Though this design of termination worked, it was realized that a loss of vacuum would compromise the electrical withstand. The most susceptible component to a vacuum integrity were the cold ceramic bushings which were under very high thermal and mechanical stress due to cryogenic temperature on one end and nearly room temperature at the other end. A slight leak in either cold bushing was sufficient to put the vacuum at the Paschen minimum for nitrogen gas, which breaks down at $\sim 250 \mathrm{~V}$, a much lower level than the operating voltage.

Due to the above reasons, a novel termination concept was conceived, designed, and built that operates with the pressurized liquid nitrogen and gaseous nitrogen as shown in Fig. 5.

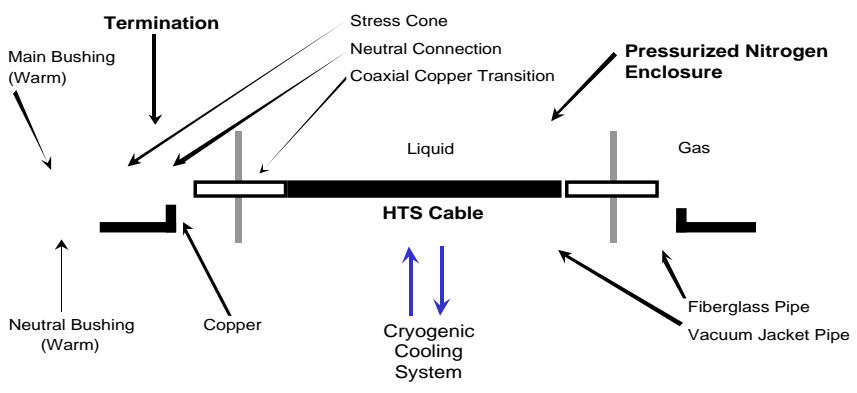

Fig. 5. Schematic of the pressurized termination concept.

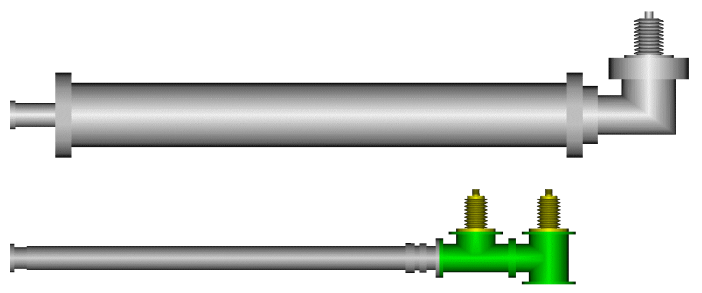

Fig. 6. Sketch of the vacuum (upper) and pressurized (lower) terminations.

This termination like the vacuum termination, is designed for $18 \mathrm{kV}$ ac withstand and $110 \mathrm{kV}$ BIL (basic impulse insulation level). The basic concept is simple: there are no cryogenics phase or shield bushings. Each termination has two conventional warm bushings which eliminates any significant thermal or mechanical stresses. The liquid nitrogen in the cable undergoes a controlled and slow phase transition to gas in the termination area. The entire termination is at the cryogenic system pressure and there is a natural thermal transition from liquid to gas along the cable conductors. The overall size of the termination is greatly reduced as shown below in Fig. 6. The Southwire HTS cable installation has used six pressurized terminations for 3 cable phases.

\section{DIELECTRIC DEVELOPMENT}

Southwire has developed a proprietary cryogenic dielectric material called Cryoflex, which is suitable for high-voltage dielectric application at low temperatures. Model dielectric cables were made and tested at ORNL to measure the ac voltage withstand and BIL. The BIL of the model cables ex- 
ceeded the requirement by $46 \%$ as shown in Fig. 7 . The average ac voltage withstand was $70.4 \mathrm{kV}$ and the withstand requirement was $18 \mathrm{kV}$ which is 2.5 times the rated line-toground voltage.

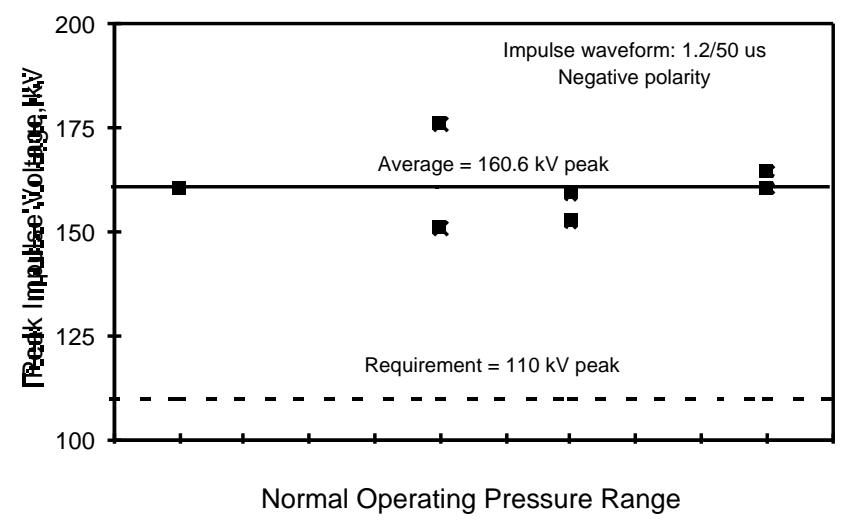

Fig. 7. The BIL level of model cables exceeded the requirement.

Aging tests are being carried out to determine the extended life of the dielectric, which is expected to go much beyond normal 30-year life for the conventional cables.

\section{SPLICE DEVELOPMENT}

A cable splice was made in the middle of a 5-m cable by joining the phase and shielding conductors as well as the dielectric materials. The splice was tested at ORNL in their cable test facility. The dc Ic of the phase conductor was about $2650 \mathrm{~A}$ at $77 \mathrm{~K}$ and $1900 \mathrm{~A}$ for shield at $80 \mathrm{~K}$. Other tests such as over-current test, voltage withstand, and BIL test are planned to be carried out. It is planned to add a splice and a 5-m cable to the 30-m cable installation during the first quarter of 2001.

\section{ELECTRICAL TESTING}

The quality of cable design, terminations, dielectric material and the performance of HTS tapes was extensively tested on 5-m cables and off line on our 30-m cables.

\section{A. 5-m Cables}

Two 5-m cables were tested in a laboratory environment during 1998 and 1999 to determine the performance and overall robustness of the system. The first 5-m cable was tested with the vacuum termination and then the second 5-m cable was tested with the pressurized termination. Both cables are the same except for some minor modifications. The following tests were made.

1) Rated Current and Voltage: The cable was operated at the designed current (1250 A ac) and voltage (7.2 kV line-toground) for extended periods of time.

2) Ac Withstand Test: The cables were subjected to an ac withstand test to $18 \mathrm{kV}$ for 30 minutes without any breakdown.

3) Impulse Testing: An impulse test was performed on the cables to determine the basic impulse insulation level.
4) Simulated Fault Current: Over-currents were applied to the cable up to $12.8 \mathrm{kA}$ for a 2 -s pulse length. This is over 10 times the design current and simulates a short circuit on the load side. The cable survived 15 simulated fault current shots without any degradation in its V-I characteristics.

5) Bend Test: A bend test was also performed. The second 5-m cable was removed from the test facility and bent in one direction and reverse direction for four cycles on a wooden fixture of the same diameter $(2.44 \mathrm{~m})$ as a cable-shipping spool. Cable testing before and after bending indicated no change in the ac withstand and impulse loading from previous tests. The cable critical current however, was reduced by about $15 \%$ after bending.

\section{B. 30-m Cable}

Off-line testing was carried out before putting the cable in service. The tests included high-voltage withstand, dc voltage/current tests, dc current load tests, and rated voltage tests. The dc voltage/current tests were repeated after six months of operation including 4 to 6 cool-down and warm-up cycles, and operating under variable load conditions.

1) Ac Voltage Withstand: An ac voltage withstand was carried out using a variable ac voltage power supply. Voltage was applied one phase at a time to $11-12 \mathrm{kV}$ and held for 30 minutes to test the cable dielectric system. Phases 1 and 2 were maintained at $166 \%$ of rated voltage without breakdown. Phase 3, which has a slightly different geometry was maintained at $230 \%$ of rated voltage without breakdown.

2) Dc Voltage/Current Test: A dc voltage/current test: was performed using ORNL's 3000 A dc power supply. The dc Ic of the phase conductor was about $2650 \mathrm{~A}$ at $77 \mathrm{~K}$ and $1900 \mathrm{~A}$ for shield at $80 \mathrm{~K}$. The dc Ic test was repeated after about six months of operation and 4 to 6 cool-down and warm-up cycles. There was no degradation in the cable Ic.

3) Extended Current Tests: Extended current tests were conducted to simulate average, rated, and emergency loading of the cables. Tests were conducted using 800, 1200, and 1400 A each for 8 hours using a dc power supply.

4) Rated Voltage Test: A rated voltage test was conducted with open-circuit using the substation supply. The cable breaker at one end was closed and the other end remained opened, so no current was flowing through the cable. The phase voltage was maintained on each phase in several sequences of up to 12 hours. The cable dielectric performed as designed.

\section{SYSTEM TESTING}

The HTS cable system was dedicated on Feb. 18, 2000 by the U.S. Secretary of Energy and the Governor of Georgia. The cable has been operated on full load for over 3000 hours by the end of Sept. 2000 and is still continuing. A data acquisition system records and archives the key parameters of the cryogenic system, electrical system, and the superconducting cable. Fig. 8 shows the variation of phase 1 current during one-month period. During the cable operation, the LN return temperature varies within 1 to $2 \mathrm{~K}$ as is shown in Fig. 9. 


\section{UTILITY APPLICATIONS}

The power demands in big cities such as New York, Chicago, Los Angeles, Tokyo, and others have increased considerably. It is essential for utilities to increase their power transmission capacities through their underground system. In the United States there are approximately 3500 miles of high-voltage underground power cables using copper or aluminum conductors to provide electricity to large metropolitan areas. The metropolitan areas continue to grow adding further demands on utilities. Most of the power cables are encased in 101.6 to $203.2 \mathrm{~mm}$ (4 to 8 in.) diameter steel pipes, which are oil-filled under high pressure. The cables in these pipes can be replaced with HTS cables, which can carry 3 to 8 times more power. It will also eliminate the environmental risks due to oil leaks.

At present, high voltage power cables bring power from the outskirts of cities to the downtown area, where transmission substations lower the voltage and distribution circuits deliver the power to customers. With this new HTS technology, the HTS cables can bring power at low voltage and high-current eliminating any need for downtown substations. The Southwire field application has successfully demonstrated the utility application of HTS cables at distribution voltages and high currents. Potential applications include: (1) substation to customer, 2) substation to substation, 3) extended substation bus, 4) substation express feeder, 5) generating unit to step-up transformer. Southwire designed their HTS cable system for distribution voltage because it easily met the demands for the operation of three manufacturing plants. Higher voltage would have required step up and step down transformers adding to the cost and time for the completion of this project. The tests on Cryoflex dielectrics have demonstrated that a higher voltage application is feasible.

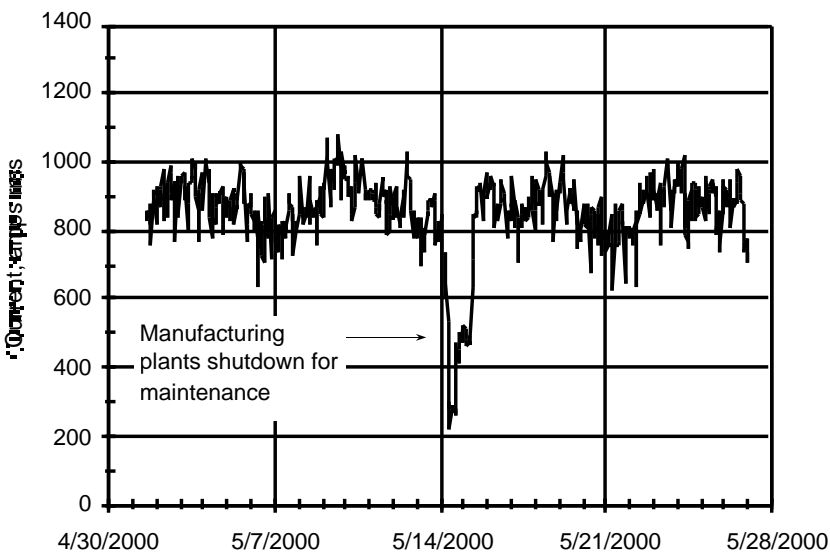

Fig. 8. HTS phase 1 current (1 hour sampling).

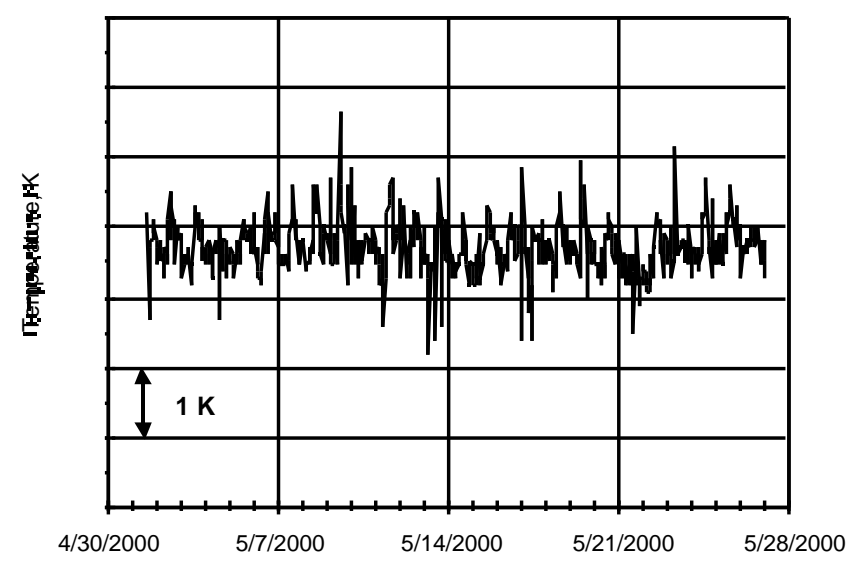

Fig. 9. Variations of return liquid nitrogen temperature for phase 1.

\section{SUMMARY}

Southwire has demonstrated an innovative cryogenic dielectric HTS cable, which is being used to transmit power to three of its main manufacturing plants. The cable has been successfully integrated into a $12.4 \mathrm{kV}$ electric distribution system and is delivering on an average over 900 A to the Southwire manufacturing plants. The cable has been reliably operated for over 3000 hours by the end of Sept. 2000 and is continuing. Test data and information is being gathered for future optimization of HTS cables. The cryogenic design of the cable has helped Southwire develop a suitable tape dielectric, which is equally suitable for higher voltage applications.

\section{ACKNOWLEDGMENTS}

The authors would like to acknowledge the talented efforts of Zach Butterworth, Ron Martin, Randy Denmon, Hugh Butler, Lewis Waters, Sammy Pollard and Gary Hyatt (all from Southwire) for their contributions in the installation of the 30-m cable system. The authors would also like to acknowledge the efforts of Jonathan Demko, Isidor Sauers, Randy James, Alvin Ellis and Vaughn Patania (all from ORNL) for their contributions in the testing to the 5-m and model dielectric cables. The authors appreciate the support and encouragement of Mr. Bob Hawsey, ORNL; Mr. Jerry Hesterlee, Southwire; and Dr. Jim Daley, DOE. This research project has been funded by Southwire Company and the U.S. Department of Energy as part of the DOE Superconductivity Partnership Initiative program.

\section{REFERENCES}

[1] U. Sinha, et. al., "Design and construction of LN2-cooled Prototype Superconducting Transmission Cable." IEEE Trans. Applied Superconductivity, Vol. 7, pp 351-354, June 1997.

[2] J. P. Stovall, et al. "Installation and operation of the Southwire 30 meter high-temperature superconducting power cable," paper 4LK04 presented at 2000 Applied Superconductivity Conference

[3] M. J. Gouge, et al. "HTS cable test facility: design and initial results," IEEE Trans. Applied Superconductivity, Vol. 9-2, pp. 134-137 (1999).

[4] J. W. Lue, et al. "5-m single-phase HTS transmission cable tests," to be published in Advances in Cryogenic Engineering, Vol. 45.

[5] M. J. Gouge, et al. "Development and testing of HTS cables and terminations at ORNL," paper 4LGa02 presented at 2000 Applied Superconductivity Conference.

[6] J. W. Lue, et al. "Fault current tests of a 5-m HTS cable," paper 2LB08 presented at 2000 Applied Superconductivity Conference. 
[7] J. A. Demko, et al. "Practical ac loss and thermal considerations of HTS power transmission cable systems," paper 2LB09 presented at 2000 Applied Superconductivity Conference.

\section{BIOGRAPHIES}

Uday K. Sinha is technical director on Southwire's HTS cable project. He has been working Southwire since 1974 after graduating from Iowa State University with a PhD in Metallurgy. He has been involved with several projects including high speed continuous casting of steel, conforming of aluminum and aluminum alloys, and quality improvements of copper rod. He holds nine US patents related to his research.

David T. Lindsay graduated from the Georgia Institute of Technology in 1996 with a BS in Materials Science and Engineering. He joined Southwire Company in 1998 as a Development Engineer where he has been working on new product designs and manufacturing processes. As a member of the superconductivity team at Southwire, he has assisted in the successful installation and startup of the HTS Cable System and works on continuing HTS development and design issues.

R. L. Hughey, Jr. is the Project Manger for Southwire HTS cable project. $\mathrm{He}$ has over 30 years of engineering and management experience with Southwire Company, having joined the company in 1972. He was involved with the development of "expert system" to help improve the accuracy and speed of many of Southwire's engineering and manufacturing processes. He has held several responsibilities at Southwire which includes, Project Manager to build Southwire's Magnet Wire plant in Osceola, Arkansas, Plant Superintendent and Plant Manger of Carrollton Utility Products plant.

John P. Stovall graduated from Rose-Hulman Institute of Technology, Terre Haute, Indiana in 1974 with a B.S. in Electrical Engineering and The Ohio State University, Columbus, Ohio in 1975 with a M.S. in Electrical Engineering. Since 1978, he has been a research staff member at Oak Ridge National Laboratory working on projects including superconducting power cables, superconducting magnetic energy storage, HVDC, distribution automation and load management. Prior to that, he worked for Public Service Company of Indiana, Plainfield, Indiana (now Cinergy/PSI)
Michael J. Gouge graduated from the United States Naval Academy with honors in 1973 with a B.S. in Physics. He completed a Ph.D. in Physics in 1984 from the University of Tennessee, Knoxville. He has been at Oak Ridge National Laboratory since 1986 working on energy programs involving cryogenic and superconducting technology. CAPT Gouge served as a nuclear submarine engineering officer and is now an engineering duty officer in the Naval Reserve working at the Office of Naval Research on advanced electric ship technology.

J. Winston Lue graduated from Taiwan Normal University with a B.S. in Physics in 1964. After teaching physics at the high school and college level, and completing a M.S. at Tsinghwa University in Taiwan, he came to the United States. In 1972, he received a Ph.D. in Physics from the University of Pittsburgh. He then worked as postdoctoral research associate at Indiana University and University of Wisconsin. He joined the Fusion Energy Division, Oak Ridge National Laboratory in 1975 where he is now a Senior Research Staff member. He worked in various stages of research and development of superconducting magnets for fusion reactors. Since 1993, he has been working in cooperation with private industry to develop high-temperature superconducting magnets and cables for electric power applications.

Pradeep Haldar is General Manager of Intermagnetics' IGC-SuperPower subsidiary, charged with conducting research and developing new business and product opportunities entailing advanced HTS technologies such as HTS fault current controllers, transformers, cable, motors and generators. In this

position, he is at the forefront of the company's efforts to commercialize surface coated HTS for power applications. Dr. Haldar has published several articles related to HTS development and is the author or co-author of over 100 technical papers. Dr. Haldar has a Ph.D. in Materials Science from Northeastern University and an MBA from Rensselaer Polytechnic Institute.

Venkat Selvamanickam is a Program Manager at IGC-SuperPower and manages materials development funded by the Air Force Office of Scientific Research, the New York State Energy Research and Development Authority (NYSERDA), DOE and DOD. He directs Coated HTS conductor fabrication effort at IGC-SuperPower, applying thin film techniques such as Ion Beam Assisted Deposition, e-beam evaporation, MOCVD and PLD. Dr. Selvamanickam has a Ph.D. in Materials Engineering from the University of Houston. Dr. Selvamanickam received the Presidential Early Career Award from the White House in 1996. This award is the highest honor bestowed by the US Government to outstanding scientists and engineers beginning their independent careers.

N.V. Vo is an HTS Manufacturing Engineer at IGC-SuperPower. He is responsible for statistical process control and characterization and analysis of HTS materials. He has a Ph.D. in Materials Engineering, a Masters Degree in Radio Astronomy and triple Bachelor degrees in Electrical and Electronic Engineering, Mathematical Sciences, and Honors Physics from the University of Adelaide, Australia. Dr. Vo has received numerous awards and has published dozens of scientific papers on high temperature superconductors and applications. He also served as a referee to several prestigious scientific journals including the Journal of Superconductivity and Journal of Materials Research. 